\title{
Learning from Failure: How to Succeed in the Chinese Retailing Market
}

\author{
You-ai Xie, Zhen Chen, Xue-Bin Huang, Shu-Ying Qiao \\ Hainan Tropical Ocean University, Sanya, China \\ E-mail: xieyouai163@163.com, chenresearch@163.com,pku.huang@qq.com,398762858@qq.com
}

\begin{abstract}
This essay aims to analyze drivers for divestment for multinational retailing companies in China: Best Buy and Home Depot and advise the American retailer, Lowe's, on how to enter the Chinese market. On the whole, Best Buy and Home Depot failed in China market mainly because of their inappropriate and unadjusted strategies. Moreover, they were unsuccessful owing to strong local and international competitors. Besides, they exited from Chinese market due to misunderstanding institutions such as weak legal regulations, business environment, and customers' need. Therefore, the recommendations are as follow. Firstly, it is wise for Lowe's to set adjustable and appropriate strategies to China. In addition, it is essential to understand Chinese business environment and customers.
\end{abstract}

Keywords-Drives for Divestment; Multinational Retailing Companies; China; Recommendations

\section{INTRODUCTION}

Emerging markets are developing countries with fast-growth economic development, attracting western organizations. Emerging markets are appealing as a result of its characteristics: lower level of economic development but high rate of growth, market size, and market consumption capacity and so on. China, one of most appealing emerging markets, has attracted various foreign investors including Best Buy, mainly because of its large population and high-growing economic development. With a highly growing of middle class customers, China is the second largest retailing market in the world at present.
However, there are barriers for foreign retail companies to enter China such as different social and cultural context [1]. In this regard, it is essential to understand a firm and Chinese market characteristics and implement proper strategies for a multinational firm.

The main purpose of this paper is to carry out an environmental analysis to suggest the retail company 'Lowe's' on how to enter into the Chinese retailing market. Therefore, a concise company introduction of Lowe's will be provided firstly. Secondly, an environmental analysis will be given, explaining chief theories in brief. Furthermore, two divestment incidents in Chinese market: Home Depot and Best Buy will be researched and compared through a cross-case analysis. On the basis of findings, recommendations on how Lowe's should enter into China will be shown in the end.

\section{SELECTED COMPANY BACKGROUND}

Lowe's company is an American retail company for home improvement, growing from a small hardware store. It is the second largest home improvement retailer in the USA, founded in 1946. Its main customers are homeowners and renters its products range from appliances to tools. Its objective is to supply the products with the most satisfactory price. In order to understand Lowe's in a deeper perspective and give more useful advice to Lowe's, environmental analysis of Lowe's will be provided by value chain (see table I )[2]

TABLE I. VALUE CHAIN ANALYSIS

\begin{tabular}{|c|c|l|}
\hline \multirow{4}{*}{$\begin{array}{c}\text { Primary } \\
\text { Activities }\end{array}$} & Logistics & -Logistically, Lowe's operates 13 distribution centers throughout North America. \\
\cline { 2 - 3 } & Operations & $\begin{array}{l}\text {-Lowe's companies operate under two platforms; the traditional brick and mortar stores as well as } \\
\text { online e -commerce sites. }\end{array}$ \\
\cline { 2 - 3 } & Market and sales & $\begin{array}{l}\text {-In North America, Lowe's has a considerable market share and presence. It is reported that an } \\
\text { increase in retail sales in the US from 144.6 billion in 2009 to 193.7 billion in 2011. However, it } \\
\text { lags behind Home Depot in the USA and has been unable to branch outside of North America. }\end{array}$ \\
\cline { 2 - 3 } $\begin{array}{c}\text { Support } \\
\text { Activities }\end{array}$ & $\begin{array}{l}\text { General } \\
\text { administration }\end{array}$ & $\begin{array}{l}\text {-Customer service within Lowe's is strength, but their customer service through e-commerce has } \\
\text { been rather lacking thus contributing to a weakness. }\end{array}$ \\
\cline { 2 - 3 } & $\begin{array}{c}\text { Human resource } \\
\text { management }\end{array}$ & $\begin{array}{l}\text {-Lowe's stores deal with many suppliers depending on the location of some of the stores. } \\
\text { - Lowe's provides a supplemental commission-pay structure with a philosophy of retaining } \\
\text { - Lowe's uses quality and knowledgeable employees. }\end{array}$ \\
\cline { 2 - 3 } & $\begin{array}{c}\text { Technology } \\
\text { development }\end{array}$ & $\begin{array}{l}\text {-Lowe's use of technological systems includes in-store-Wi-Fi, touch screen technology, and } \\
\text { barcodes that customers can use to access information on their smart phones. Nevertheless, it } \\
\text { cannot utilize the technology boom in smart phones for promotion purpose. }\end{array}$ \\
\cline { 2 - 3 } & Procurement & -Lowe's procures its merchandise from approximately 7,000 domestic and foreign suppliers. \\
\hline
\end{tabular}




\section{ENVIRONMENTAL ANALYSIS}

It is vital to understand how performance and strategies is influenced by internal and external factors. A combination of these factors in making strategies helps firms to get sustainable competitiveness and succeed in markets.

Internal Analysis: The resource-based view regards resources as essential to distinguished performance for an organization. The resources include tangible resources that are physical and intangible resources. These resources enable a company to achieve and maintain competitive advantages if they display VRIO1characteristics [3]. It is stated that to convert a temporary competitive advantage into a sustained competitive advantage, resources are necessary to be heterogeneous and immobile.

External Analysis: The industry-based view deals with how a company's strategy and performance is affected by industry conditions. Due to external competitive factors, there is competition with an industry. Relying on the dimension of competitive forces, the intensity of competiveness among existing competitors varies [4].

The institution-based view, a third leg of the strategy tripod, plays a vital role in determining strategies. Institutions are constraints that affect human behaviors. In this sense, institutions can be categorized into formal and informal constraints. Formal institutions regard to written rules including regulatory laws, regulations, economic and political contracts etc. On the other hand, informal institutions are considered as unwritten constraints such as normative and cognitive cultures, ethical norms, values and social behavior and so on[5].

\section{DRIVERS FOR DIVESTMENT-TWO EXPLANATORY CASES}

A company can adapt a divestment strategy by selling a proportion of business or close a part of business operations. There are various reasons why firms choose to divest. Firstly, a common reason is that acquired business underperformed. Besides, some corporations divest in order to gain more funds to attain better investment opportunities since their resources are limited [6]. In this part, two cases of withdraw will be analyzed to disclose the drivers for divestment strategy.

Case1: Best Buy. Best Buy Co., Inc. is a multinational electronics retailer established in the USA who provides consumer electronics, appliances, and technology services. It operates big-box retail stores, online retail operations and call centers in the US, Canada, China and so on [7]. However, Best Buy failed in China market. In 2006, to expand its Chinese market, it acquired Jiangsu Five Star, a fourth largest retailer of consumer electronics in China. At the end of 2006, Best Buy opened its first brand big-box store in Shanghai. In 2009; Jiangsu Five Star became a

1 VRIO is an abbreviation for value, rarity, imitability and organization (Rothaermel, 2013). wholly owned subsidiary of Best Buy. Unfortunately, in 2011, Best Buy closed all wholly owned brand stores in China because of its poor operational management [8].

Firstly, inside Best Buy, it was uncompetitive in China. To begin with, it lost competitive, partly because of its inappropriate pricing strategy in China. Identical products were sold at higher price than competitors because of elevated services. It was thought that elevated service would be its comparative advantage. However, the service Best Buy provided in China can be found at the convenience stores with cheaper price. Therefore, consumers tend to purchase the exact same products from local retailers at cheaper price. In addition, Best Buy lagged behind competitors in the Chinese market, partially due to lack of brand recognition in China. This affected its sales performance negatively because Chinese consumers prefer to purchase products from famous retailers. Furthermore, it failed, in part because it maintained the same business model as that in America. This was not effective in China. For example, it kept no-commission or fixed price policy in China.

Secondly, within the big box electronics retail industry, the intensity of rivalry is high in China. First of all, existing leading companies set higher barriers to new entrants invisibly. For example, there are two major local competitors: Gome and Sunning. With well-developed brands and formed oligopolies, both have more than 100 chain stores in various cities in China, and have very strong wholesalers or distributors within provinces to supply identical inventories at lower price. Another prime competitor is Apple whose electronic products are differentiated. Even though prices of products in Apple store are higher, its products are differentiated and popular. Thus, under stiff competition, it was not easy for Best Buy to expand in Chinese market with same products at higher prices. In addition, the bargaining power of Chinese customers is high, because consumers can buy undifferentiated products from various retailers online or in stores[9]. This increases competition within an industry. Furthermore, substitutions to electronics in China are high because of e-commence retailers such as JingDong Mall, big-box home improvement retailers like Home Depot, and digital content distributors such as iTunes.

Thirdly, within institution context, Best Buy failed to adjust to Chinese consumers' purchasing behavior. First, Chinese consumers are accustomed to free value-added service provided by retailers after they purchase products, as retailers in China usually provide many value-added services for free. However, Best Buy chose to charge customers for its service. And also, Chinese customers tend to bargain. Bargaining is common when they purchase products in life. Nevertheless, Best Buy adopted fixed price policy. It meant bargaining was not an option. Consequently, most Chinese consumers would not select Best Buy; instead, they prefer to buy products from local retailers like Gome and Sunning, because they can negotiate with the salesperson to get a discount there. Moreover, Best Buy was 
unsuccessful to understand Chinese salespersons' selling need, reducing sales and profits. In fact, Sale staff in China generally sells particular brands to obtain commission [10]. However, using no-commission policy, Best Buy created more ethical environment to train salesperson to be trusty and unbiased like in the USA, which is not effective in China.

Case 2: Home Depot. Home depot is the largest retailer in the world for home improvement, established in the USA in 1978. Its products include appliances, building materials and furniture and so on. Home Depot maintains price low and provides relatively high quality to customers. With approximately 2200 big-box stores, it operates in countries such as US, Canada and Mexico. In 2006, it extended to China by acquiring 12 stores from the Home Way, a local company. But at the end of the third quarter of 2012, Home Depot exited China after six-year losses [11].

From an organization perspective, Home Depot failed, principally because it maintained do-it-yourself business model. This model is applied and better suited to Home Depot companies in the US. In contrast, the Chinese customers are not satisfied with this kind of model, not only because the labor cost is fairly low in China, but also because Chinese market is not only pure do-it yourself market. Namely, Chinese consumers are currently necessary to and eagle to learn how to decorate home and experience western culture in do-it-yourself model. If Home Depot sell products at low cost and give guidance to customers, it would be more popular and attractive in China, thereby gaining competitive advantage [12]. Additionally, it was a loser in the China market partly owning to its suburban location. Inconvenient location led the company to lose middle-class Chinese customers who live in downtowns and have stronger purchasing power.

From an industry-based view, the competition is stiff in terms of existing competitors. For example, there is a prime international competitor, IKEA. IKEA, the largest furniture company, is the popular brand and accounts a large market share in China. Even though Ikea and Home Depot have the same business model in China, the former outperforms the latter because IKEA provides low cost assembling service for customers and guides them. Apart from international retailers, there are a range of local direct rivals such as QM and Quanu, and indirect rivals like TaoBao and Gome. In addition, Chinese customers have a strong bargaining power since there are various international and local home-improvement retailers in China.

From an institutional aspect, firstly, Home Depot retreated from China, because it could not understand and use Chinese business environment appropriately. More specifically, Chinese people focus on relationship called "Guan Xi" in Chinese. With weak formal institution in China, there is a grey area. Businessmen who have a better relationship with government officials would get more favor from the Chinese government in the same situation. Nevertheless, restricted by US laws, Home Depot cannot establish a better relationship with government officials in illegal ways like bribery, and thus cannot secure more favor from the Chinese government. Secondly, Home Depot existed from China, because it could not understand the lifestyle of child-generation from middle-class. Young people from middle-class are the main customers for home improvement companies, because a majority of them purchase houses or departments in China when they prepare to get married. However, Home Depot did not realize that these young people are seldom hands-on and have enough funds from their parents to hire professional staff to help them decorate home. Besides, they regard lower price products as low-end products without considering quality if the products are not famous. These factors affect the consumers not to choose Home Depot to a large extent. Thirdly, Home Depot failed in Chinese market, because it could not interpret Chinese consumer mentality thoroughly. Specifically, DIY model is normally considered to serve for poor people since manual labor is cheap and has been despised in China. As a result, Home Depot lost relatively wealthy customers in China who are concerned with social status [13]. Moreover, the Chinese middle class is brand conscious, but Home Depot is nearly unknown in China. See table 2 .

TABLE II. Cross-Case Analysis

\begin{tabular}{|l|l|l|}
\hline & Best Buy & Home Depot \\
\hline Differences & $\begin{array}{l}\text {-Entry mode: } \\
\text { at the very beginning: acquisition; } \\
\text { later: wholly-owned enterprise } \\
\text {-High price: products are too expensive. }\end{array}$ & $\begin{array}{l}\text {-Entry mode: Acquisition } \\
\text {-Low price: products are regarded as low-end products } \\
\text { for poor customers. }\end{array}$ \\
\hline Similarities & $\begin{array}{l}\text {-They were both successful multinational companies from the United State. } \\
\text {-They did not adjust their strategies to Chinese culture, considering all global markets are identical. } \\
\text {-Their brands were both not famous in China. } \\
\text {-They faced stiff competition from local retailers. } \\
\text {-Their customers have strong bargaining power. } \\
\text {-They both entered Chinese market by acquisition. } \\
\text {-They existed from China due to poor operational management. }\end{array}$ \\
\hline
\end{tabular}




\section{V.SUMMARY AND RECOMMENDATIONS}

Based on the above analysis, a conclusion can be drawn that retail industry is attractive but competitive for multinational firms in China. Therefore, foreign retail companies are required to carefully examine their own characteristics and Chinese market features to gain competitive advantages and choose appropriate strategies. For Lowe's, there are several suggestions on entering the Chinese retail market. To begin with, Lowe's should set appropriate strategies. Firstly, Lowe's should adjust its business model to Chinese culture. Both Home Depot and Best Buy imported business models from the USA companies. However, the unadjusted business models were not compatible with Chinese culture. This resulted in failure. And thus, Lowe's is suggested to choose do-it-for-me business model. Moreover, like Best Buy and Home Depot, it is better for well-capitalized Lowe's to enter the Chinese market by acquisition, because companies acquired will help it do business with local distributors. Therefore, Lowe's can purchase inventories at lower price. And also, through acquiring a local company, it is easier to become a famous brand by advertisements. In addition, Lowe's is indicated to open stores in city centers in developed cities. This is because most middle-class consumers who have greater ability to afford to buy its products live in city centers in developed cities.

Secondly, Lowe's is supposed to develop good relationships with suppliers and government officials before entering Chinese market, as with weak formal institution, Chinese business focuses more on relationship with partners. As for suppliers, for instance, since Lowe's operates in the USA, Canada and Mexico, it can cooperate with Chinese suppliers in its North American market as well, so that it can establish reliable and solid relationships with Chinese suppliers. As a result, it perhaps enables to negotiate with Chinese suppliers to get identical inventories at lower price. As for government officials, as USA law is not allowed USA companies to bribery Chinese officials, Lowe's is able to make efforts to sponsor programs for public good to get support from Chinese government. With support from Chinese government, for instance, Chinese government may give priority to choosing store locations. Last but not least, Lowe's should get better understanding of Chinese consumers. Generally, customers choose brands they are familiar with and make a purchase before comparing price of the same product in several shops. That is why both Home Depot and Best Buy failed. Therefore, Lowe's should advertise that its brand is a relatively luxury and its brand represents highly cost effective products, so that Chinese are acquainted with its name and buy its products. These recommendations probably help Lowe's to enter into Chinese market in a more effective way. Nevertheless, they cannot guarantee that Lowe's can be successful in China.

\section{ACKNOWLEDGEMENT}

This research was financially supported by the Hainan Province Philosophy and Social Science Planning Project, China (Grant NO. HNSK (YB) 16-13) and the Hainan Province Higher Education Institution Reform Funds, China (Grant NO. HNJG2015ZD-13).

\section{REFERENCES}

[1] Y. Niu, L. Dong, and R. Chen, "Market entry barriers in China", Journal of Business Research. vol. 65, pp.68-76, 2012.

[2] Lowes Companies, 2015. Lowes Companies - Investor Relations Home. [Online]. Available at http://phx.corporate-ir.net/phoenix $\cdot$ zhtmlc=95223\&p=irol-irhome [Accessed Mar. 11, 2015].

[3] F. Rothaermel, Strategic management, 1st ed., McGraw-Hill Irwin, New Work, 2013.

[4] M.E. Porter, "The Five Competitive Forces That Shape Strategy" Harvard Business Review, vol.86, pp. 23-41, 2008.

[5] E. Garrido, J.Gomez, J, and J. Maicas, and R. Orcos, "The institution-based view of strategy: How to measure it", BRQ Business Research Quarterly. vol.17, pp. 82-101, 2014.

[6] H. Berry, "Why do firms divest?", Organization Science, vol.21, pp 380-396, 2010.

[7] Best Buy, (2015). About Best Buy. [online] Available at: https://corporate.bestbuy.com/about-best-buy/ [Accessed Mar. 15, 2015].

[8] Istockanalyst. (2015). Best Buy closes China outlets, poor grasp of local market blamed. [online] Available at: http://www.istockanalyst.com/article/viewiStockNews/articleid/4912 539 [Accessed Mar. 15, 2015].

[9] S. Rein. (2011). Why Best Buy Failed in China. [online] CNBC.Available at: http://www.cnbc.com/id/41882157 [Accessed Mar. 16, 2015].

[10] Warrington College of Business Administration. (2015). Best Buy China. [online] Available at: http://bear.warrington.ufl.edu/oh/IRET/Cases/Best_Buy_China_Case _Revised.pdf [Accessed Mar. 15, 2015].

[11] Corporate. homedepot, (2015), Home. [online] Available at: https://corporate.homedepot.com/OurCompany/History/Pages/default .aspx [Accessed Mar. 18, 2015].

[12] L. Burkitt. (2012). Home Depot Learns Chinese Prefer 'Do-It-for-Me'. [online]WSJ. Available at: http://www.wsj.com/articles/SB100008723963904444335045776510 72911154602 [Accessed Mar. 18, 2015].

[13] M. Gao, "Culture Determines Business Models: Analyzing Home Depot's Failure Case in China for International Retailers from a Communication Perspective", Thunderbird International Business Review, vol.55, pp.173-191, 2013. 